\title{
Evaluación de la competencia comunicativa de los docentes de la Universidad Pedagógica Nacional Francisco Morazán
}

Enviado: 12 de noviembre de 2020 / Aceptado: 16 de diciembre de 2020

Publicado: 30 de diciembre de 2020

SONIA PATRICIA GUITY LÓPEZ

Departamento Centro de Investigación e Innovación Educativas, Universidad Pedagógica Nacional Francisco Morazán, Honduras

(iD) https://orcid.org/0000-0003-4178-6823

sguity@upnfm.edu.hn

MANUEL SORIANO FERRER

Departamento de Psicología Evolutiva y de la Educación,

Universidad de Valencia, España

manuel.soriano@uv.es

\section{RESUMEN}

El presente estudio examinó la competencia comunicativa de 181 docentes de la Universidad Pedagógica Nacional Francisco Morazán de Honduras. Los docentes cumplimentaron un instrumento para valorar sus habilidades lingüísticas (e.g. competencias gramaticales, discursivas, sociolingüísticas y estratégicas) y su autopercepción acerca de sus capacidades discursivas en su desempeño docente (e.g. como buen emisor, receptor, comunicador en el aula, participante en reuniones y asesor académico). Los resultados indicaron que los docentes poseían un nivel medio de las habilidades lingüísticas gramaticales, sociolingüísticas y estratégicas, aunque más de la mitad de los docentes (57.5\%) obtuvieron un nivel bajo en su competencia discursiva. Sin embargo, los docentes se auto percibieron con unas capacidades

\section{ABSTRACT}

The evaluation of the competences in Heritage Education of students of the Degree of History of the University of Malaga

The present study examined the communicative competence of 181 teachers from the Francisco Morazán National Pedagogical University of Honduras. Teachers completed an instrument to assess their linguistic abilities (eg grammatical, discursive, sociolinguistic and strategic competences) and their self-perception about their discursive abilities in their teaching performance (eg as a good transmitter, receiver, communicator in the classroom, participant in meetings and academic advisor). The results indicated that the teachers had a medium level of grammatical, sociolinguistic and strategic linguis- 
discursivas como docentes muy elevados. Por último, se encontraron diferencias significativas en función del grado académico de los docentes, siendo los que ostentaban el grado de doctor los que alcanzaron un mayor nivel en competencia comunicativa.

Palabras Clave: competencia comunicativa, docentes educadores, lengua materna. tic skills, although more than half of the teachers (57.5\%) obtained a low level in their discursive competence. However, the teachers perceived themselves as having very high discursive capacities as teachers. Finally, significant differences were found depending on the academic degree of the teachers, with those who held the degree of doctor the ones who reached a higher level in communicative competence.

Keywords: communicative competence (languages), teacher educators, native language.

\section{INTRODUCCIÓN}

La Unión Europea impulsa en mayo de 1998, mediante la Declaración de La Sorbona, el Espacio Europeo de Educación Superior (EEES), que pretendió postular un nuevo sistema universitario que tuviera como eje el aprendizaje, armonizar la estructura de las titulaciones y aplicar sistemas comunes de compatibilizar y evaluar el aprendizaje. Para ello, se realizaron en las universidades participantes, modificaciones en sus planes de estudio, para que los estudiantes, pudieran obtener habilidades, actitudes y conocimientos, independientemente del país europeo en el que se haya formado. Dos de las propuestas más relevantes fueron el Proyecto Tuning y el Marco Común Europeo de Referencia para las Lenguas (Martínez, 2011).

El Proyecto Tuning como estrategia metodológica, implementó el Enfoque por Competencias, cuya clasificación más amplia, se refiere a competencias genéricas y otras, específicas, que todo graduado universitario debe evidenciar. Tanto en las competencias genéricas como en las específicas, se enfatiza en la comunicación oral y escrita en lengua materna y en una segunda lengua, como habilidad esencial para interrelacionarse con los demás, resolver conflictos, buscar información, incrementar las capacidades de comprensión, sensibilidad y conocimiento (González y González, 2008).

En la Universidad Pedagógica Nacional Francisco Morazán (UPNFM) es la única institución nacional dedicada a la formación docentes en los niveles de Educación Prebásica, Básica y Diversificado. En ella se implementó a partir de 2009 el enfoque por competencias para ingresar en la dinámica de los cambios de la Educación Superior a nivel mundial y en particular, en el ámbito latinoamericano, en países como Colombia, México, Perú, Venezuela y Argentina, en donde es posible localizar, varias instituciones de nivel superior, que adoptaron el enfoque 
por competencias en sus planes de estudio (Núñez, 2016). En Honduras no se ha realizado hasta la fecha, ninguna investigación para indagar sobre el enfoque por competencias en el ámbito universitario, solamente las dos realizadas por la UPNFM, es decir, no se encuentran indagaciones nacionales sobre este tema. En la UPNFM se ha tratado de manera científica el enfoque por competencias. El primero de los estudios, de Almendares et al. (2015) y el otro, realizado por la Dirección de Evaluación y Acreditación en 2017, que es una unidad académica de esta misma universidad. En ambos casos, los resultados sobre competencia comunicativa, oscilaron entre niveles bajo e intermedio, evidenciando poco desarrollo de esta competencia en estudiantes universitarios de la carrera de español (Universidad Pedagógica Nacional Francisco Morazán, 2017).

La Competencia Comunicativa no es un constructo nuevo en educación, surgido por el Proyecto Tuning, sino que, desde hace décadas atrás, en diferentes países del mundo, se han realizado diversos estudios experimentales para conocer la didáctica, el aprendizaje y los sistemas de evaluación empleados en el ámbito de las lenguas. Lo que sí constituye novedad, es el creciente interés por considerar la lengua como una herramienta genérica, útil y necesaria en todos los ambientes educativos y laborales en los cuales, se inserte una persona, como una de las principales aspiraciones del Espacio Europeo de Educación Superior.

Los primeros estudios sobre la Competencia Comunicativa datan de 1960 con el lingüista Noam Chomsky, quien introduce los conceptos de competencia-actuación, referido estrictamente a la habilidad lingüística del hablante (Ronquillo y Goenaga, 2009). Más adelante en 1971, el norteamericano Hymes, amplía la connotación lingüística de Chomsky, e incorpora la dimensión social y psicológica, dando lugar a los diversos sectores: competencia sociolingüística, estratégica y discursiva.

Posteriormente, Canale y Swain (1980) proponen primero una estructura teórica de tres elementos (Gramatical, Sociolingüístico y Estratégico) y luego, Canale (1983) señala finalmente, cuatro componentes que guiaron esta investigación: "dígase competencia gramatical o lingüística, competencia socio-lingüística (registro, variedades lingüísticas y reglas socio-culturales), competencia discursiva (cohesión y organización del texto) y competencia estratégica (elementos verbales y no verbales que sirven de soporte y compensación en la comunicación" (Ronquillo y Goenaga, 2009, p.4).Tomando en consideración estos teóricos y las respectivas clasificaciones, seleccionamos una definición bastante amplia pero precisa de cómo entender la competencia comunicativa.

La Competencia Comunicativa (CC) se define como la habilidad que posee un hablante para saber qué decir y cómo hacerlo en un contexto comunicativo determinado. Las personas que 
tienen un alto nivel de competencia comunicativa pueden lograr su propósito comunicativo (informar, persuadir, entretener) haciendo las modificaciones y adaptaciones pertinentes en su lengua oral y/o escrita para desarrollarse eficientemente en su comunidad lingüística. Durante muchas décadas se creyó que era una capacidad exclusiva de y para los docentes de lenguas (tanto en una lengua materna como en una segunda lengua), en los últimos años en diferentes contextos, se han realizado indagaciones que señalan que la competencia comunicativa como una habilidad fundamental en el desempeño docente (Aguirre, 2015; Ayllon et al., 2017; Castellanos, 2015; Corredor, 2011; Gallego et al., 2013; Joshi y Wijekumar, 2019; Lozano et al., 2013).

Debido a la evolución del término de Competencia Comunicativa se encontraron diversos estudios que muestran a nivel mundial, el incremento de las investigaciones sobre este tema, haciendo énfasis en uno o varios de los elementos o componentes definidos por los principales autores, anteriormente citados y muchos más, para esta indagación, se decidió emplear la clasificación de Canale, por considerarla más completa y sobre todo, que propició la realización de un estudio global sobre el desempeño comunicativo de los docentes de la UPNFM. Se explican a continuación, los componentes de la competencia comunicativa, bajo los cuales se realizó la indagación:

Para Canale (1980) la competencia gramatical, incluye "el léxico, la morfología, la gramática oracional, la semántica y la fonología” (p.16). La competencia gramatical, también puede ser definida como "la capacidad cognitiva que le permite a una persona convertir sus representaciones mentales en palabras y combinarlas para producir textos” (Menegotto, 2016, p.1). Para evaluar la competencia gramatical, el Marco Europeo de referencia de las lenguas, propone varios mecanismos diferentes, para registrar los avances de los estudiantes, en síntesis, diferentes formas de evaluación: "evaluación de aprovechamiento, de dominio, continua, en un momento concreto, formativa, sumativa, de la actuación, directa, indirecta" (Villavicencio y Rivero, 2019, p. 334).

Respecto, a la competencia Estratégica, Docsity (2017) señala que "es una de las competencias que intervienen en el uso efectivo de la lengua por parte de una persona" (p. 4). Particularmente, el concepto de competencia estratégica ha transitado por discusiones teóricas, que algunos consideran inacabadas, planteada por Wolff (1998) y recogida luego por Martín (2002) que identifica tres (3) dimensiones del término Estrategia: la psicológica, la didáctica y la técnico-cultural. De estas tres dimensiones, ha adquirido más relevancia, la didáctica, relacionada con modos de actuación planeados que el aprendiz puede poner en marcha de manera más o menos consciente y cuyo fomento en el aula influye positivamente en su comportamiento (Martín, 2002). 
Por otro lado, el factor o subcomponente sociolingüístico, implica el uso socialmente adecuado de la lengua, para emitir enunciados apegados a las normas de uso y de discurso, es así que, esta competencia se define como: "el conjunto de conocimientos y destrezas necesarias para alcanzar un uso de la lengua apropiado a un contexto social y a un entorno cultural determinado" (Moreno, 2007, p. 62). La Sociolingüística se ocupa principalmente del estudio de las variaciones de uso de una lengua, dentro de una comunidad determinada, Starc (2011). Para emplear eficazmente una lengua, debe considerarse al individuo en su dimensión social, es decir, considerando su edad, sexo, clase social, creencias, valores, etc. Es por ello que, Canale y Swain (1981), incorporaron al estudio de la competencia comunicativa, este importantísimo factor, que resulta determinante, en la adquisición y desarrollo de la competencia comunicativa.

Finalmente, la competencia discursiva se define como "la capacidad de interaccionar lingüísticamente en el marco de un acto de comunicación, captando o produciendo textos con sentido, que se perciban como un todo coherente y adecuado a la situación y al tema"(Fernández, 2010, p.351). Con relación a esta competencia, muchas disciplinas demostraron su interés en el análisis del discurso, llamado también texto, como la ciencia cognitiva, la inteligencia artificial y la antropología, así como, la lingüística textual, la semiótica, el análisis del discurso y el conversacional, la sociolingüística interaccional y la pragmática (Calsamiglia et al., 1989).

Algunos estudios sobre competencia comunicativa la han abordado desde las cuatro subcompetencias anteriormente señaladas, pero en otros estudios como los de (García, 2008; Gallego y Rodríguez, 2010; Gallego et al., 2013) han estudiado esta competencia solamente con la subcompetencia discursiva, en el plano de la expresión oral del desempeño docente, tanto en estudiantes de magisterio como en los profesores en servicio, señalando cinco principales habilidades comunicativas de la expresión oral como buen emisor, buen receptor, comunicador en el aula, participante en reuniones y asesor académico. Las competencias como emisor tienen como propósito evaluar, las habilidades de los docentes como hablantes al emitir mensajes claros, y precisos en su comunicación con los estudiantes. Respecto a las competencias como receptor, se propone valorar, las destrezas lingüísticas de los docentes cuando escuchan los mensajes emitidos por sus estudiantes, colegas o cualquier integrante de la comunidad universitaria.

Las competencias como comunicador en el aula, están encaminadas a estimar las destrezas de los docentes en los procesos lingüísticos que diariamente desarrolla en su aula de clases, de manera particular, el léxico empleado, la organización del discurso y la articulación fonética fonológica. En las competencias como participante en reuniones, se propone esti- 
mar, las habilidades de los docentes para comunicarse con sus colegas, es decir, al diálogo interprofesional que se efectúa constantemente entre docentes, ya sea, a nivel formal o informal.

La competencia como asesor académico, se conjugan las habilidades como emisor y receptor, así como, el uso adecuado del tono, la expresión facial y corporal y la capacidad persuasiva del docente, orientado a los estudiantes en temas relacionados con la ejecución del flujograma de su carrera y otros asuntos similares.

Para orientar la presente investigación, se decidió después de la revisión de la literatura, considerar los cuatro componentes de la competencia comunicativa: gramatical, discursivo, sociolingüístico y estratégico, así como, las habilidades discursivas de la expresión oral propuestas por Gallego et al., 2013), para construir un instrumento más complejo y que visualizara, el nivel de desarrollo de la competencia comunicativa de los docentes participantes.

En síntesis, el constructo de competencia comunicativa ha evolucionado a lo largo del tiempo. Sin embargo, los estudios que han analizado la competencia comunicativa de los docentes han sido limitados y escasos, ya que se han centrado en la evaluación de sus competencias lingüísticas (Aguilar, 2016; Balada, s.f; Moreno, 2007; Menegotto, 2016; Martín, 2009) y en menor escala, en las competencias discursivas de la expresión oral (Gallego et al.,2013; Ayllon et al., 2017; Fernández, 2010). Por estas razones, en el presente trabajo nos planteamos: determinar el nivel de las competencias lingüísticas a nivel gramatical, discursivo, sociolingüística y estratégico; y analizar la autopercepción que tienen los docentes de su competencia estratégica.

\section{MATERIAL Y MÉTODO}

\subsection{Participantes}

En este estudio participaron 181 docentes de la Universidad Pedagógica Nacional Francisco Morazán, de los cuales 161 pertenecen a la sede central, ubicada en la ciudad capital, y que constituye el centro universitario más grande y mejor estructurado y 20 docentes a la sede regional de San Pedro Sula. En cuanto a la edad de los participantes, sus edades oscilan entre los 26 y los 74 años, es decir, el docente más joven que labora en la UPNFM tiene 26 años, y el mayor, 74 años.

En la tabla 1 se recogen las principales características sociodemográficas de los docentes participantes: grado académico, carrera que estudió en el Pregrado (de la facultad de humanidades, ciencia y tecnología, o una carrera fuera de este ámbito de formación), tipo de univer- 
sidad donde estudió el pregrado y el postgrado (pública o privada), país en donde estudió el pregrado (Honduras o en el extranjero).

Tabla N¹. Características de la Muestra de Docentes Participantes

\begin{tabular}{lllll}
\hline Variable & & & & Total \\
\hline Grado Académico & Licenciatura & Maestría & Doctorado & 181 (100\%) \\
& $18(9.9 \%)$ & $123(68.0 \%)$ & $40(22.1)$ & \\
\hline Carrera de Pregrado & Facultad de & Facultad de & Otras \\
& Humanidades & Ciencia y & especializaciones \\
& $94(52 \%)$ & Tecnología & 19 (10.5\%) \\
& & $68(38 \%)$ & \\
\hline Tipo de Universidad donde estudió Pregrado & Pública & Privada & \\
& $174(96.2 \%)$ & 7 (3.9\%) & \\
\hline País donde estudio su Pregrado & Honduras & Extranjero & \\
& $171(94.5 \%)$ & $10(5.5 \%)$ & \\
\hline Tipo de universidad donde estudió Postgrado & Pública & Privada & \\
& $142(78.4 \%)$ & $39(21.5 \%)$ & \\
\hline
\end{tabular}

\subsection{Instrumento}

En la elaboración del instrumento para valorar el nivel de competencia comunicativa de los docentes, se siguieron cuatro pasos: a) revisión de la literatura sobre escalas empleadas para evaluar la competencia comunicativa; b) selección de la escala diseñada por Gallego y Rodríguez (2013) y solicitud de autorización, vía correo electrónico para hacer uso de la misma; c) elaboración de ítems para valorar las habilidades gramaticales, discursivas, sociolingüísticas y estratégicas de los docentes; d)revisión por expertos nacionales de los ítems propuestos y ajustes respectivos en la redacción final de los mismos en base a las recomendaciones de los expertos.

Como se mencionó en el primer paso, tras revisar literatura existente sobre instrumentos empleados para evaluar el nivel de competencia comunicativa, se reflexionó sobre qué escala o test podría aplicarse, que evaluara las cuatro dimensiones con sus distintos sub-indicadores seleccionados en el marco metodológico, esto es, competencia gramatical, discursiva, sociolingüística y estratégica como elementos claves para lograr una valoración completa de esta competencia en docentes. No se localizó un instrumento que llenara completamente nuestra expectativa metodológica y que fuese factible de aplicar en el contexto de la educación superior 
con docentes universitarios, es por ello, que se decidió, estructurar un instrumento proveniente de varias fuentes: la primera fuente fueron los 48 ítems elaborados por Gallego et al. (2013) que valora únicamente la competencia estratégica que tiene a su vez, cinco subcompetencias relacionadas con el desempeño comunicativo del docente: Subcompetencias como Emisor, Receptor, Comunicador en el aula, Participante en reuniones y Asesor académico. Estos ítems se tomaron sin mayores modificaciones del instrumento original y se empleó la misma escala tipo Likert de tres puntos: (1=escaso/nulo; $2=$ satisfactorio; $3=$ elevado), cada docente se autoevaluó en esta parte del instrumento, marcando la opción que consideró adecuada según su práctica docente. Un ejemplo del ítem empleado: Escucho atentamente, las interrogantes planteadas por el estudiante: Elevado/ Suficiente/Escaso o nulo.

La segunda fuente fue la investigación realizada por la Dirección de Evaluación y Acreditación de la Universidad Pedagógica Nacional Francisco Morazán, de la cual, se tomaron 12 ítems, empleados para valorar también la competencia estratégica y que fueron utilizados en estudiantes universitarios de la carrera de español, quienes estaban por finalizar su carrera de pregrado en esta universidad, estos ítems tuvieron otro formato de pregunta con cuatro opciones de respuesta, una correcta y tres incorrectas. Estos ítems también fueron valorados por expertos, quienes aprobaron su aplicación en docentes universitarios los cuales, giraron en torno a tres textos en tres formatos diferentes de lectura, audio y video, donde se le solicitó al docente, elegir la respuesta que considerara correcta, conforme a su comprensión lectora, para citar un ejemplo: ¿Cuál es la función más importante del lóbulo Parietal? a) Controla la memoria visual y auditiva b) Regula el ritmo de los movimientos c) Centrada en el movimiento y el cálculo y d) Determina la visión. La respuesta correcta es el inciso A.

La tercera y última fuente empleada fue el diseño y validación de varios ítems que pudieran evaluar las competencias lingüísticas restantes (gramatical, estratégica y sociolingüística) para ello, se elaboraron varios ítems y fueron evaluados por expertos nacionales del área de lingüística, quienes señalaron la pertinencia, adecuación y coherencia de 10 ítems, con la misma estructura de opción múltiple, una respuesta correcta y tres erróneas. Para el diseño de estas preguntas, se seleccionó un fragmento de una novela española, El juego del ángel, y se redactaron preguntas para valorar la competencia gramatical, estratégica y sociolingüística, basadas en la lectura del texto, un ejemplo de estos ítems es el siguiente: En el texto siguiente: Si, tras la purga, el individuo reincidía, don Basilio lo apuntaba a la sección de labores del hogar a perpetuidad. La palabra SI, indica: a) consecuencia b) condición c) explicación d) distribución. La respuesta correcta era el inciso $\mathrm{B}$. 
Adicionalmente a estos ítems, se añadieron 8 para recoger datos sociodemográficos de los docentes participantes.

En síntesis, el instrumento final empleado para valorar la competencia comunicativa estuvo compuesto por 78 ítems. Con la muestra actual, el instrumento alcanzó una fiabilidad total de .86 , siendo adecuada para un instrumento educativo.

\section{RESULTADOS}

Para facilitar la comprensión de los resultados se presentaran primero, los resultados de los docentes en relación a sus habilidades lingüísticas gramaticales, discursivas, sociolingüísticas y estratégicas. Luego, los resultados de la autopercepción del docente en la subcompetencia estratégica relacionada con sus habilidades como emisor, receptor, comunicador en el aula, participante en reuniones y como asesor académico. Por último, presentaremos las diferencias en competencia comunicativa en función del grado académico.

\subsection{Resultados de los docentes en cuanto a sus habilidades lingüísticas}

En la tabla 2 presentamos los resultados obtenidos por los docentes de forma global. Para determinar el nivel de desempeño de competencia comunicativa, se establecieron cuatro niveles de rendimiento de los docentes en función del porcentaje de éxito en las diferentes tareas empleadas en la evaluación de la competencia comunicativa. Así, se consideró como nivel nulo/muy bajo un rendimiento $0-25 \%$, un nivel bajo del $26-50 \%$, un nivel medio del $51-75 \%$ y un nivel alto del 76-100\%.

Tabla N². Nivel obtenido por Competencia Lingüística de los Profesores

\begin{tabular}{lllll}
\hline Subcompetencias & Nivel Nulo & N. Bajo & N. Medio & N. Alto \\
& $\mathbf{0 - 2 5 \%}$ & $\mathbf{2 6 - 5 0 \%}$ & $51-75 \%$ & $\mathbf{7 6 - 1 0 0 \%}$ \\
\hline Gramatical & & $75.2 \%$ & \\
\hline Discursiva & & $57.5 \%$ & \\
\hline Sociolingüística & & $60.65 \%$ & \\
\hline Estratégica & & $63.2 \%$ & \\
\hline
\end{tabular}

De manera general, puede afirmarse que el nivel de las habilidades lingüísticas de los docentes participantes fue medio en las cuatro habilidades lingüísticas, gramatical, discursiva , sociolingüística y estratégica. También se destaca en la tabla 2, que ninguno de los docentes haya obtenido un nivel alto en sus competencias lingüísticas. 
En un análisis más pormenorizado, en cuanto a la competencia gramatical, presentamos destacados en negrita los porcentajes de los aciertos de los profesores. Especial mención merece el bajo porcentaje de aciertos, sólo un 39.2\% en el ítem 9. En otras palabras, el $60.8 \%$ de los profesores no fue capaz de determinar en el orden correcto, las categorías gramaticales presentes en el fragmento. En el resto de ítems de competencia gramatical, el porcentaje de aciertos estuvo por encima del $80 \%$ como puede observarse en la tabla 3 , alcanzando los profesores un nivel promedio de competencia gramatical (75.2\%) muy cercano a un nivel alto.

Tabla $\mathbf{N}^{\circ}$ 3. Resultados Subcompetencia Gramatical de los Profesores

\begin{tabular}{llllll}
\hline Subcompetencia Gramatical & A & B & C & D & Nivel \\
\hline Ítem 9 & 5.0 & $47 \%$ & $39.2 \%$ & $8.8 \%$ & Bajo \\
\hline Ítem 10 & $3.3 \%$ & $90.1 \%$ & $4.4 \%$ & $2.2 \%$ & Alto \\
\hline Ítem 11 & $.6 \%$ & $10.5 \%$ & $87.8 \%$ & $.6 \%$ & Alto \\
\hline Ítem 12 & $2.8 \%$ & $84.0 \%$ & $6.6 \%$ & $6.6 \%$ & Alto \\
\hline Promedio & & & $\mathbf{7 5 . 2} \%$ Medio &
\end{tabular}

En relación a la subcompetencia discursiva los profesores apenas alcanzaron el 57.5\%, que se corresponde con un nivel medio. En otras palabras, el $42.5 \%$ de los profesores proporcionó respuestas erróneas o incorrectas, indicando que no fueron capaces de identificar correctamente la función de una conjunción dentro de un fragmento de texto.

Respecto a la competencia Sociolingüística, los profesores mostraron resultados variados en el desempeño de esta habilidad, oscilando entre nivel bajo y alto, se alcanzó un mejor desempeño en el ítem 15 en determinar la intención comunicativa del texto, y menos éxito en identificar la relación entre personajes (ítem 14), la forma de tratamiento (ítem 16) y el tipo de saludo (ítem 17), son interesantes estos datos, ya que, podrían indicar que los docentes en general, no prestan demasiada atención o no manejan con pericia esos aspectos de la interacción social, o no saben reconocerlos de manera clara en un texto, ello podría indicar que esta habilidad no ha sido suficientemente desarrollada en los docentes participantes, implicando serias limitaciones en la comprensión del ámbito sociocultural, tanto del estudiante como del profesor mismo; quien no posee habilidades suficientes para interactuar con sus alumnos, ello es un contrasentido preocupante, ya que, el docente debe caracterizarse por su facilidad para comunicarse con los demás, especialmente, con los de su entorno cultural, y estos resultados reflejan una carencia importante en la formación docente, como puede observarse en la tabla 4, aunque en promedio alcanzaron un nivel medio en esta habilidad. 
Tabla N4. Resultados de la Subcompetencia Sociolingüística de los Profesores

\begin{tabular}{llllll}
\hline Subcompetencia Sociolingüística & A & B & C & D & Nivel \\
\hline Ítem 14 & $4.4 \%$ & $12.2 \%$ & $25.4 \%$ & $\mathbf{5 8 . 0 \%}$ & Medio \\
Ítem 15 & $6 \%$ & $19.9 \%$ & $3.9 \%$ & $\mathbf{7 5 . 7 \%}$ & Alto \\
Ítem 16 & $44.2 \%$ & $7.7 \%$ & $\mathbf{4 4 . 8 \%}$ & $3.3 \%$ & Bajo \\
Ítem 17 & $2.2 \%$ & $33.1 \%$ & $64.1 \%$ & $.6 \%$ & Medio \\
Promedio & \multicolumn{2}{c}{$\mathbf{6 0 . 6 5 \% \text { Medio }}$}
\end{tabular}

En cuanto a los resultados de la subcompetencia estratégica, los profesores alcanzaron también un nivel promedio, un 63.2\% de aciertos. Sin embargo, en un análisis más pormenorizado, como puede observarse en la tabla 5, los profesores oscilaron en los diferentes ítems entre un nivel bajo, medio y alto. En concreto, los profesores mostraron un nivel bajo a la hora de identificar la idea principal del texto (ítem 18) y a la hora de determinar la función principal del cerebro (ítem 73). Por el contrario, los profesores alcanzaron un nivel alto a la hora de seleccionar las razones que le daban importancia al personaje de la rana (ítem 67) y a la hora de determinar la influencia política de la televisión (ítem 77).

Tabla $N^{\circ} 5$. Resultados Competencia Estratégica de los Profesores

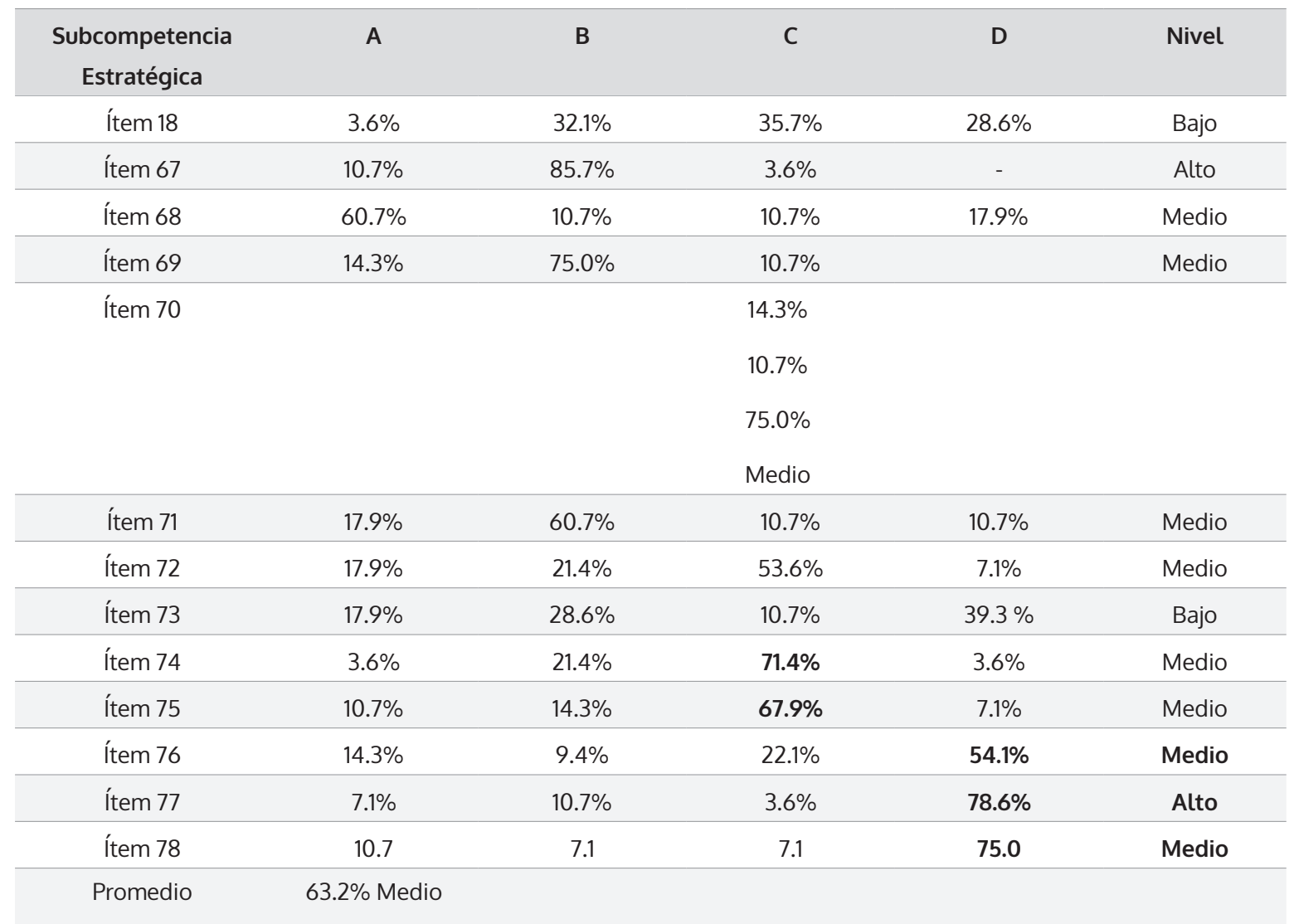




\subsection{Resultados de los docentes sobre su autopercepción de su competencia estratégica}

Respecto a la autopercepción docente en esta competencia, se tomaron en cuenta los 48 ítems antes señalados y se realizó la suma de valores del puntaje total de estos ítems dando 234 puntos, con ello se elaboró una escala ad-hoc para determinar el nivel de competencia comunicativa así: 0-76 para un nivel escaso o nulo, 79-156 nivel suficiente y 157-234 para un nivel elevado, como puede observarse en la siguiente tabla 6, los docentes de la UPN, obtuvieron en su autopercepción, un nivel elevado en la subcompetencia estratégica, el detalle de los porcentajes se muestra a continuación:

Tabla N6. Nivel de Autopercepción de la Competencia Estratégica de los Docentes Participantes

\begin{tabular}{lll}
\hline Nivel & Frecuencia & Porcentaje \\
\hline Suficiente & 35 & $19.3 \%$ \\
\hline Elevado & 146 & $80.7 \%$ \\
\hline Total & 181 & $100.0 \%$ \\
\hline
\end{tabular}

Tomando en consideración, el promedio general de las habilidades lingüísticas (tabla 2) y en el nivel de autopercepción de la competencia estratégica (tabla 6) puede señalarse que los profesores participantes en este estudio poseen un nivel "medio" en su competencia comunicativa. Para determinar este nivel, se sumó el promedio de las subcompetencias lingüísticas con el promedio del nivel de autopercepción de la competencia estratégica y se dividió entre dos, dando como resultado $72.4 \%$ que corresponde a un nivel medio, los datos completos de los porcentajes se presentan en la tabla 7 .

Tabla $N^{\circ}$ 7. Nivel general de Competencia Comunicativa de los Docentes de la UPN

\begin{tabular}{|lll}
\hline Subcompetencias lingüísticas & Subcompetencia Estratégica & Total \\
\hline $64.1 \%$ & $80.7 \%$ & $72.4 \%$ \\
\hline
\end{tabular}

\subsection{Resultados en Competencia Comunicativa en función del Grado Académico de los docentes}

Los resultados del análisis de las variables sociodemográficas del instrumento, mediante el análisis de un factor (Anova), señalan que, no hubo diferencias estadísticamente significativas en la competencia comunicativa en función de la edad y el sexo de los docentes participantes. Sin embargo, el ANOVA realizado sobre la competencia comunicativa encontró diferencias estadísticamente significativas entre los docentes participantes en función de su grado acadé- 
mico (licenciatura, maestría y doctorado), $(\mathrm{F}(3,625)=2.178, p \leq .029, \eta 2=, 039)$ con un tamaño del efecto mediano.

La prueba Post Hoc HSD de Tukey (véase tabla 8) señala que las diferencias en competencia comunicativa se encuentran entre los docentes que ostentan el grado de doctorado y el resto de titulaciones (licenciatura y maestría), entre las que no hubo diferencias significativas (véase tabla 8). Así, son los docentes que ostentan el título de doctor, los que obtuvieron un nivel significativamente más alto en sus competencias comunicativas.

Tabla N8 . Prueba Post hoc para Grado Académico de los Participantes

\begin{tabular}{ccccc}
\hline $\begin{array}{c}\text { (I) Grado académico } \\
\text { de los participantes }\end{array}$ & $\begin{array}{c}\text { (J) Grado académico } \\
\text { de los participantes }\end{array}$ & $\begin{array}{c}\text { Diferencia de } \\
\text { medias (I-J) }\end{array}$ & DT & Sig. \\
\hline Licenciatura & Maestría &,- 71 & 3,169 &, 037 \\
\hline Maestría & Doctorado & $-12,89 *$ & 5,185 &, 973 \\
\hline Licenciatura &, 71 & 3,169 &, 027 \\
\hline Doctorado & Doctorado & $-12,18 *$ & 4,673 &, 037 \\
\hline & Licenciatura & $12,89 *$ & 5,185 &, 027 \\
\hline
\end{tabular}

\section{DISCUSIÓN}

El primer objetivo de esta investigación fue determinar el nivel de la competencia gramatical, discursiva, sociolingüística y estratégica de los docentes participantes de la Universidad Pedagógica Nacional Francisco Morazán.

Los datos revelaron que, en general, alcanzaron un nivel medio, empleando una escala adhoc para determinar el nivel obtenido, primero en cada subcompetencia lingüística y luego, de manera global. En la subcompetencia Gramatical se obtuvo un 75.2\% (medio), en la subcompetencia Discursiva un nivel de 57.5\% (medio), en la subcompetencia Sociolingüística un nivel de $60.6 \%$ (medio) y en la subcompetencia Estratégica, un nivel de $63.2 \%$ (medio), y un promedio global de $64.1 \%$, que también es un nivel medio en las habilidades lingüísticas ya mencionadas. 
Los datos obtenidos por los docentes, indican un desempeño limitado de las habilidades lingüísticas, que se asume deberían lograrse en un nivel alto, ya que, el docente diariamente, desarrolla procesos comunicativos, tanto con sus estudiantes, como con sus colegas, personal administrativo y técnico que labora en la universidad. Otros estudios que han evaluado la competencia comunicativa, solo han hecho énfasis en la competencia estratégica y no, en las habilidades lingüísticas gramaticales, discursivas y sociolingüísticas. En Honduras, no se efectúan evaluaciones de capacidades lingüísticas de los docentes, solamente de los estudiantes de educación primaria y secundaria, por lo que, esta información obtenida representa un punto de partida para otorgarle más importancia al dominio de estas capacidades del lenguaje.

En el sistema educativo se ha partido de la premisa que una vez que el docente esté ejerciendo su profesión, dispone de todas las herramientas necesarias para desempeñarse exitosamente, por tanto, los procesos de capacitación que se desarrollan, se enfocan en temas sobre evaluación, herramientas metodológicas, innovaciones tecnológicas, y más recientemente, sobre educación remota, debido a la situación de pandemia que se experimenta a nivel mundial por el coronavirus.

En otros estudios sobre la competencia comunicativa (García et al., 2010) los datos revelaron que los estudiantes de magisterio consideran que poseen un nivel insuficiente (es decir, bajo en nuestra escala), mientras que los estudiantes de magisterio participantes en el estudio de Gallego y Rodríguez ( 2010) mostraron un nivel suficiente de competencia comunicativa. Estos datos discrepan con nuestros resultados. Aunque es difícil y arriesgado señalar razones contundentes que expliquen tales diferencias, quizá podrían deberse a que los estudiantes tienen menos reparos en admitir sus debilidades y errores que los mismos docentes con experiencia, que a veces se enfocan más en el desarrollo de la programación establecida de su espacio pedagógico, que en los procesos comunicativos que se puedan producir en el aula de clases, reservando esta tarea, para los profesores de lengua (español e inglés).

Con relación al siguiente objetivo del estudio, la medición de la autopercepción de su competencia comunicativa, los resultados mostraron que el nivel de escaso no obtuvo ningún porcentaje de autovaloración, el nivel suficiente logró un 19.3\%, y el nivel elevado alcanzó un nivel de 80.7\%. Ello significa que el 80\% de los docentes participantes, tienen una autopercepción "elevada" sobre su competencia comunicativa. Con estos resultados, es posible tratar de establecer semejanzas y diferencias entre nuestros resultados y los obtenidos por Gallego y Rodríguez (2010) y García et al. (2013), quienes obtuvieron de manera consistente, un nivel suficiente en sus resultados. 
La discrepancia con nuestros resultados, puede deberse a distintas razones. Una de ellas, podría estar relacionada con la forma de auto percibir el dominio de una habilidad lingüística, ya que para muchos docentes la competencia comunicativa solamente está referida a la expresión oral o la escrita, sin mayor trascendencia o incidencia en la labor docente, y que, además, es una tarea exclusiva para los docentes del área de las lenguas. La otra razón podría ser la variabilidad del pregrado que ostentan los docentes de la UPN, en donde puede observarse una pluralidad de titulaciones no relacionadas directamente con la carrera docente como ingenierías (Industrial, Sistemas, Ambiental), Psicología, Sociología, Pedagogía, Mercadotecnia, Cine, Dra. Ciencias Químicas y Farmacia, etc. que, sin duda, pudieron influir en la autopercepción y adquisición de la competencia comunicativa de los docentes participantes en el contexto hondureño. Quizá el hecho de pertenecer a titulaciones no relacionadas con la formación docente haga que no sean tan conscientes de su competencia comunicativa, mientras que los otros estudios al pertenecerlos participantes a las distintas áreas de la formación docente sean más conscientes y críticos sobre sus competencias comunicativas (Gallego y Rodríguez, 2010; García et al., (2013).

\section{CONCLUSIONES}

Los resultados obtenidos en el estudio, mostraron en general que los docentes de la Universidad Pedagógica Nacional Francisco Morazán, obtuvieron en la competencia comunicativa un nivel medio, que indica que es necesario, atender de manera inmediata, el desarrollo de esta competencia, ya que, tratándose de una universidad formadora de docentes, se aspira a que su nivel sea elevado, para garantizar que los docentes sean buenos comunicadores, dentro y fuera de sus aulas, para que enseñen apropiadamente su área de formación, así como, para incidir positivamente como modelo de habla para sus estudiantes.

Un nivel medio en la competencia comunicativa, significa entonces que medianamente, los docentes de esta universidad, están cumpliendo su propósito comunicativo; como institución educativa pionera en la formación docente a nivel nacional, debe avanzar hacia la consecución de un nivel elevado en la competencia comunicativa docente, por ello, debe comenzarse a despertar conciencia de que esta habilidad ha tomado mayor importancia en los últimos años y que cada docente, debe procurar su mejor desarrollo.

En la misma dirección, otro hallazgo significativo del estudio fue que ninguno de los docentes participantes, lograron un nivel alto en su competencia comunicativa, siendo congruente con la idea antes planteada, pero señalando enérgicamente, que representa una situa- 
ción problemática que debe resolverse, ya que, se espera que los docentes, posean altas todas sus habilidades interpersonales, sociales, laborales y por supuesto, lingüísticas.

Décadas atrás, este resultado quizás no hubiese sido preocupante, debido a que el énfasis en la tarea docente, fue la transmisión de conocimiento y la utilización de métodos y recursos didácticos, pero, en la actual sociedad del conocimiento, las valoraciones sobre algunas habilidades y destrezas docentes es distinta y se le concede mayor importancia. a las capacidades lingüísticas y sociales que muestren a un profesor, capaz de comunicarse y relacionarse amigablemente con su entorno educativo, cultural y social.

Considerando estos resultados obtenidos, se propone un Plan de Mejora para que los docentes evaluados y todos aquellos, que decididamente deseen participar, fortalezcan su competencia comunicativa. Este plan se implementará dentro de la plataforma Moodle que emplea la universidad, con dos estrategias claramente definidas: El Objeto de Aprendizaje y la Hipermedia. En ambas, la competencia comunicativa es concebida como un objeto mediático por la tecnología, para motivar la interacción docente con un conjunto de actividades creativas para desarrollar su competencia comunicativa.

El Objeto de Aprendizaje se concibe como un objeto mediático que, empleando la tecnología, convierten a los objetos digitales en espacios creativos para producir conocimiento. Todo Objeto de Aprendizaje debe contar con tres elementos constitutivos: Contenidos, Actividades de Aprendizaje y Elementos de Contextualización. los Objetos de Aprendizaje conocidos como por su abreviatura de OA, se comenzó a emplear desde la década de los 70, y se define como "objetos digitales o no digitales que pueden ser utilizados, reutilizados o referenciados durante el aprendizaje apoyado por tecnología” (Ramírez, et al. 2014, p.112).

En la primera estrategia del Objeto de Aprendizaje, podemos encontrar una variedad de actividades de lengua, para trabajar cada competencia lingüística, desde ejercicios más tradicionales, como completar textos y ordenar frases y oraciones, hasta sopas de letras, crucigramas, laberintos, juegos interactivos, que presentan una faceta lúdica del aprendizaje de esta competencia.

La segunda estrategia que se sugiere integre este Plan de Mejoras, es la Hipermedia, resultante de la combinación entre un hipertexto y la multimedia, dando como producto un conjunto de nodos enlazados con textos, imágenes, sonidos, presentaciones, animaciones, lecturas, etc. (Arellano, 2007). La hipermedia consiste en combinar el texto con elementos sonoros o visuales en la misma presentación, es decir, que no tiene una estructura secuencial, el docente puede decidir, conforme a su interés, si comenzar con el texto, o con los audios, 
imágenes, animaciones, videos, gráficos, ejercicios interactivos, actividades de comprensión lectora, etc. Que puedan conformar cada hipermedia, esta se ubicaría en la Plataforma virtual, con la que ya cuenta los docentes de la UPNFM, y en la cual, también todos tienen acceso.

Como parte de esta estrategia, se ofrecen videos, imágenes, canciones y lectura de poesía, para que los docentes desarrollen sus habilidades lingüísticas de forma interactiva y también lúdica, rompiendo el esquema tradicional de un aprendizaje de una lengua, repetitivo y de bajo impacto en la adquisición de destrezas y capacidades lingüísticas.

Creemos que un plan de mejoras con estas características, resulta más atractivo y motivador para los docentes, que el diseño de ciclos de capacitaciones teóricas que, en la mayoría de los casos, no generan aprendizajes significativos ni se replican en las aulas de clases.

Es necesario destacar que, hasta la fecha, no se han desarrollado planes o programas de mejora de la competencia comunicativa, ni en esta universidad ni en ninguna otra de las instituciones de educación superior en el país, por lo que, esta propuesta es pionera en la determinación de trabajar de manera sistemática, esta competencia. En las escuelas y colegios a nivel nacional, se implementan actividades para desarrollar la competencia comunicativa de los estudiantes, no así, para los docentes de ningún nivel educativo, por lo que, este plan de mejoras ofrecerá oportunidades y espacios de trabajo interactivo para que los docentes, conforme a su disponibilidad horaria, puedan realizar las actividades y ejercicios planteados.

Nuestro Plan de Mejora ofrece, además: a) variedad de ejercicios prácticos que no requieren de conocimientos especializados en comunicación b) Actividades flexibles que se ajustan a la disponibilidad horaria del docente c) Pueden realizarse desde cualquier dispositivo electrónico (celular, tabletas, laptop, computadoras de escritorio) d) Actividades que brindan retroalimentación inmediata, porque indica la respuesta correcta de cada ejercicio, luego de su realización e) El docente puede tomar las actividades varias veces hasta alcanzar un nivel óptimo en sus capacidades comunicativas, compitiendo consigo mismo para mejorar sus habilidades f) cada profesor puede determinar el orden y seguimiento de sus actividades comunicativas, ya que, no se estableció un patrón fijo de inicio y finalización del curso g) todo profesor de esta universidad puede tomar el curso, independientemente de su especialidad, años de servicios y tipo de contrato. En suma, nuestro plan de mejoras brinda un espacio digital, variado y atractivo para motivar a los profesores a que puedan mejorar sus habilidades lingüísticas.

Este plan de mejora cuenta con el apoyo de la Rectoría, quien, en todo momento, apoyó la realización de este estudio, reconociendo la relevancia de la competencia comunicativa en la formación docente, se contó, además con el apoyo de la Dirección de Tecnologías de la In- 
formación, que es una unidad técnica, responsable de la plataforma moodle de la universidad, para la creación del curso sobre competencia comunicativa.

Finalmente, esta investigación también reveló que los docentes con grado académico de doctorado, evidenciaron mejores resultados en su competencia comunicativa, indicando entonces que, esta universidad debe continuar apoyando y promoviendo, la formación de doctores en las distintas áreas del saber humano, ya que, los docentes con este grado, han desarrollado mejor, sus habilidades comunicativas, producto sin duda, del riguroso proceso de producción científica, que caracteriza a los programas de doctorado, independientemente del país de procedencia. Actualmente, la legislación interna de la universidad, establece como requisito de contratación, el grado de Maestría, no obstante, creemos que debe proseguirse en la exigencia de promover progresivamente, que la planta docente, cuente con titulación de doctorado. Para ello es necesario, la construcción de un plan de formación académica, que identifique las actuales titulaciones y que organice en cohortes, los grupos docentes que serán apoyados en sus estudios doctorales.

\section{REFERENCIAS BIBLIOGRÁFICAS}

Aguirre, D. (2005). Reflexiones acerca de la competencia comunicativa profesional. Educación Media Superior, 19 (3), 1-10.

Arellano, A. (2007). El aprendizaje basado en la Web para desarrollar la competencia oral comunicativa en estudiantes de inglés como lengua extranjera. Tesis de Maestría. Universidad de Los Andes.

Almendares, R., Rivas, K., y Sorto, S. (2015). Opiniones de los estudiantes de la UPNFM sobre las competencias comunicativas necesarias para el profesor de Lengua y Literatura. Edit. SEU.

Ayllon, M., Gallego, J. Gómez, I. y Rodríguez, A. (2017). Competencia Comunicativa de los Futuros Docentes durante su Formación Inicial. REMIE, 2 (1) 1-34.

Balada, R. (s.f.). La competencia gramatical con todos los sentidos en las clases de EFE. Centro Virtual Cervantes, 199-205. Recuperado de https://cvc.cervantes.es/ensenanza/biblioteca ele/diccio ele/diccionario/competenciagramatical.htm

Canale, M. (1981). De la competencia comunicativa a la pedagogía comunicativa del lenguaje. Recuperado de https://cvc.cervantes.es/ensenanza/biblioteca_ele/antologia_didactica/enfoque comunicativo/canale01.htm 
Castellanos, J. (2015). Competencia comunicativa en los estudiantes de Práctica Profesional III como complemento integral en la formación docente. Revista Ciencias de la Educación. 26 (47).

Canale, M. (1983). De la competencia comunicativa a la pedagogía comunicativa del lenguaje. Recuperado de https://cvc.cervantes.es/ensenanza/biblioteca ele/antologia didactica/enfoque comunicativo/canale01.htm

Canale, M y Swain, M. (1980). Theoretical Bases of Communicative. Approaches to Second Language Teaching and Testing. Applied Linguistics 1(1), 1-48.

Chomsky, N. (1957). Estructuras sintácticas. Edit. Siglo XXI.

Carrillo, E. y Cortés, J. (2010). La Competencia comunicativa. Piedra angular. Synthesis, 8(15), 37-43.

Corredor, Y. (2011). Competencias comunicativas: Cátedra esencial en la formación del estudiante universitario. Cuadernos de Revista Hispánica, 18 (18), 113-134.

Calsamiglia, H. y Tusón, A. (2004). Las Cosas del decir. Ariel.

Díaz, A. (2006). El Enfoque de Competencias en Educación. ¿Una alternativa o un disfraz de cambio? Claves. 18 (111), 7-36.

Dirección de Evaluación y Acreditación (2017). Nivel de desarrollo de la competencia comunicativa en estudiantes de Práctica Profesional II del Profesorado en la Enseñanza del Español de la Sede Central y el CURSPS, en coherencia con las competencias establecidas en el perfil de egreso. Edit. SEU.

Docsity. (2017). Diccionario de términos clave de ELE. Obtenido de https://www.docsity.com/es/cvcdiccionario-de-terminos-clave-de-ele-3/2213412/

Fernández, S. (2010). La Competencia Discursiva. Monográficos, 11, 351-383.

Gallego, García, Segovia y Rodríguez (2013). Competencias comunicativas de maestros en formación. Profesorado. Revista de Currículum y Formación del Profesorado, 14 (2), 303-323.

González. V. y R. González. (2008). Competencias genéricas y formación profesional: Un análisis desde la docencia universitaria. Revista Iberoamericana de Educación, (47), 185-209.

Hymes, D. (1972). On Communicative Competence. Penguin.

Joshi, R. Malatesha, y R., Wijekumar, K. (2019). Introduction: teacher perception, self-efficacy and teacher knowledge relating to literacy. Ann. of Dyslexia 69, 1-4.

Lozano, A., Rosales, B. y Zarate J. (2013). Desarrollo de la competencia comunicativa en el idioma inglés en una plataforma interactiva. Revista Electrónica Sinéctica, (41) 1-11.

Martín, S. (2002). La integración de la competencia estratégica en el currículo de lengua extranjera. Disponible en https://rua.ua.es/dspace/bitstream/10045/6082/1/ELUA 20 11.pdf 
Martínez, J. (2011). Desarrollo histórico del Espacio Europeo de Educación Superior a través de los documentos, encuentros y declaraciones. Cuarto Congreso Internacional sobre Historia y Ciencias Sociales del 5 al 23 de mayo de 2011. Málaga, España.

Menegotto, A. (2016). Reflexiones sobre la competencia gramatical y su relación con la competencia comunicativa. VI Jornadas de Español como Lengua Segunda y Extranjera. Ensenada, Argentina.

Moreno, F. (2007). Adquisición de segundas lenguas y Sociolingüística. Revista de Educación, 343 (5), 55-70.

Núñez, J. (2016). El modelo competencial y la competencia comunicativa en la Educación Superior en América Latina. Foro de Educación. 14 (20), 467-488.

Ramírez, M. Rodríguez, N., y Romero, S. (2014). Objeto de aprendizaje para la formación docente orientado al desarrollo de competencias de comunicación. Evsal Revostas, 15 (2) 108-130.

Ronquillo y Goenaga (2009). Competencia Comunicativa: Evolución Cronológica del término y sus elementos constitutivos. Revista Humanidades Médicas, 9 (1), 1-14.

Starc, M.(2011). El desarrollo de la Competencia Sociolingüística en la clase de español.Disponible en https:// www.researchgate.net/publication/283494827 El desarrollo de la competencia sociolinguistica_en_la clase de espanol_como_lengua extranjera/link/563abc7108ae45b5d284b609/ download

Universidad Pedagógica Nacional Francisco Morazán (2017). UPNFM. Sitio oficial de la UPNFM. Edit. SEU.

Villavicencio, Simón y Rivero, L. (2019). La evaluación de la competencia comunicativa en los cursos de español como lengua extranjera. Transformación. 15 (3), 330-341.

Wolff, D. (1998). Estrategias de aprendizaje: un camino hacia una mayor autonomía del alumno. Recuperado de http://paedpsych.jk.uni-linz.ac.at/4711/lehrtexte/lehrtexte.html 